\title{
Studies Practice Survey of Chinese Wushu Communication in World Chinese Education
}

\author{
Weihua Liu \\ College of Physical Science, Jishou University, Hunan Jishou 416000, China \\ xxhw1916@aliyun.com
}

\begin{abstract}
Keywords: Wushu; Chinese education; Communication; Survey; Countermeasures
\end{abstract}
\begin{abstract}
Through integration of Chinese Wushu into Chinese language education, Chinese language learning can be more three-dimensional, and Chinese international promotion channels can be more diversified, which can not only make full use of existing educational resources, but also help to achieve better results for Chinese culture communication in the process of internationalization. Based on this, through actual observation and field survey of the Chinese Wushu in Chinese language education, combined with the experience of personal participation in Chinese education, by means of literature analysis, field investigation, theoretical speculations and other research methods, in-depth research on Chinese Wushu communication in world Chinese education was conducted and it can be found that there are many practical problems for the Chinese Wushu communication in Chinese education, such as the lack of corresponding materials for Wushu dissemination, the single content of Wushu communication, lack of high-quality Wushu disseminators, and stagnated theoretical research. At last, this paper has proposed corresponding communication strategies based on these issues for the hope that Chinese Wushu will be widely spread in the "global village".
\end{abstract}

\section{Introduction of Chinese Education}

Chinese Education. What is Chinese education? Maybe many people are not veryclear about this. There are various explanations in the academic circles are alsodifferent opinions. Many experts and scholars hold different opinions and views. Somescholars believe that Chinese language education is Chinese language education aiming at foreigners. Also, some scholars proposed that Chinese education is for overseas Chinese people's language education. Due to the rapid development of modern Chinese language education, many scholars have a new interpretation of Chinese language education in the new era. Chinese education as a special form of education has evolved up to nowadays with the progress of the times and socio-economic development into a more mature form of education including humanities, language, history, and geography as a comprehensive and comparative education. The content covers the economic, social, political, ethnic, and cultural fields of overseas Chinese people the world ${ }^{[1]}$. In summary, the author has proposed his own point of view that Chinese language education refers to the process of conducting Chinese cultural knowledge education on overseas Chinese and Chinese people from all over the world (the abbreviation of foreign nationals who have joined or acquired the Chinese nationality of their country's nationality. All Chinese mentioned later in the article refer to this), as well as non-Chinese, including various Chinese language training institutions, Confucius Institutes, Confucius Classrooms, overseas Chinese schools, Chinese schools, overseas Chinese language schools, Chinese language schools, and other educational institutions spreading Chinese culture as the main content.

History of Chinese Education. Chinese language education emerged at earliest abroad with its historical origin to be traced back to the "Ming Cheng Academy" ${ }^{2]}$, established by the overseas Chinese in Batavia (now Jakarta, Indonesia) in 1690 about more than 320 years ago. At that time, Ming Cheng Academy was a private school for teaching literacy. With the property of free school, it was the product of the formation of overseas Chinese communities with the purpose and content of teaching to teach local Chinese and their children to read. It can be considered as the prototype of modern Chinese education. After the Opium War, a huge amount of Chinese people made a living 
overseas, and slowly formed a group dominated by Chinese people in various places of the world, such as the Chinese community, Chinese Street, Chinatown, etc. Meanwhile, Overseas Chinese Association, the organization safeguarding the interest of the Chinese was born. To solve the problem of local Chinese children's education, local overseas Chinese associations raised funds to set up their own schools - Overseas Chinese Schools, Chinese Language Schools, Chinese Language Schools. Through this, overseas Chinese language education has gradually developed in an organized and large scale. At this time, overseas Chinese people still serve as the main body of Chinese education with the teaching content expanded to to some Chinese traditional cultures, such as the Three-character Classics, the Book of Family Names, Four Books and Five Classics, and Abacus. With the development of the times, Chinese language education has gradually perfected and diversified with its audience of more than just overseas Chinese and ethnic Chinese. Gradually attacting non-Chinese people with love for Chinese culture, its purpose and content has also developed from originally simple language teaching to disseminate various traditional Chinese cultures, such as Chinese history, Chinese geography, Chinese folk dance, Chinese Wushu, etc. From the perspective of educational space, there exist nor only overseas Chinese education but also domestic Chinese language education schools and institutions targeting at returned overseas Chinese and non-Chinese people such as Chinese Language and Culture College of Huaqiao University, Collee of Chinese Language and Culture, Jinan University, Yunnan Chinese Language and Culture College of Yunnan Normal University, etc.

Under the correct leadership of the Communist Party of China, and the accelerating pace of reform and opening up, increasing frequency of international exchanges and improving overall national strength, constant enhancement of political, cultural, educational, diplomatic, and other soft powers, the world is paying more attention to China image and other aspect, which leads to a growing upsurge in learning Chinese culture around the world and stir up a "Chinese fever".

\section{Practical survey of Wushu Communication Process in World Chinese Education}

The traditional Chinese language education mainly focuses on language teaching but ignores the teaching content of other Chinese cultures. Later, under the guidance and suggestions of the leaders of the Overseas Chinese Affairs Office and the delegations of overseas Chinese and overseas Chinese, overseas Chinese have gradually carried out the dissemination of traditional Chinese cultural contents beyond Chinese languages such as Wushu, ethnic dance, and Chinese opera. Due to the e diverse and lively form, strong practicalness, and rich ethnic cultural style of ethnic traditional cultural form, the most important thing is that they are deeply favored by students, in particularly Wushu is very popular among overseas students.

Practical Survey of Wushu Communication in Domestic Chinese Education.Since 2002, the Overseas Chinese Affairs Office and the Overseas Exchange Association and various Chinese language education bases throughout the country have carried out the "Root-seeking Trip" summer (winter) education camp activities ( Table 1) each year throughout the country with the theme of "Learning Chinese Martial Arts" and other Chinese traditional cultures. The characteristic travel education form combining sightseeing tour with culture and education is well received by overseas students, thus greatly increasing students' interest in Chinese culture learning. At the same time, as it is easy to carry out this form of education and its popularity among students, it is also favored by Chinese and overseas Chinese education schools and bases. Activities like this are increasing every year. 
Table 1 Statistic table of "Root-seeking Trip" summer (winter) education camp activities with Wushu as the major communication content ${ }^{(1)}$

\begin{tabular}{|l|l|l|l|}
\hline Time & Location & Topic & $\begin{array}{l}\text { Number of } \\
\text { participant }\end{array}$ \\
\hline August 2002 & Beijing & Chinese Wushu & 800 \\
\hline July 2005 & Beijing & Chinese Wushu & 800 \\
\hline December 2005 & Guangdong Guangzhou & Chinese Wushu & 300 \\
\hline December 2006 & Guangdong Guangzhou & Chinese Wushu & 344 \\
\hline July 2007 & Beijing & Chinese Wushu & 230 \\
\hline December 2007 & Guangdong Guangzhou & Chinese Wushu & 385 \\
\hline December 2008 & Hainan Haikou & Chinese Wushu & 205 \\
\hline December 2008 & Hunan Changsha & Chinese Wushu & 150 \\
\hline July 2010 & Henan Songshan & Shaolin Wushu & 50 \\
\hline December 2011 & Henan Songshan & Shaolin Wushu & 100 \\
\hline December 2011 & Hunan Changsha & Chinese Wushu & 150 \\
\hline December 2011 & Jiangsu Nanjing & Chinese Wushu & 50 \\
\hline July 2012 & Henan Songshan & Shaolin Wushu & 110 \\
\hline December 2012 & Shaanxi Xi'an & Wushu & 100 \\
\hline July 2013 & Henan Songshan & Shaolin Wushu & 60 \\
\hline July 2013 & Zhejiang Wenzhou & Wushu & 40 \\
\hline Decembe 2013 & Guangdong Foshan & Wushu & 24 \\
\hline December 2013 & Henan Songshan & Shaolin Wushu & 100 \\
\hline July 2014 & Zhejiang Wenzhou & Chinese Wushu & 40 \\
\hline July 2014 & Henan Songshan & Shaolin Wushu & 112 \\
\hline May 2014 & Fujian Quanzhou & Chinese Wushu & 70 \\
\hline July 2014 & Fujian Quanzhou & Chinese Wushu & 192 \\
\hline July 2014 & Fujian Quanzhou, Xiamen & Chinese Wushu & 200 \\
\hline July 2014 & Qingdao, China & Chinese Wushu & 115 \\
\hline July 2015 & Shanghai & Chinese Wushu & 500 \\
\hline July 2015 & Zhejiang Wenzhou & Wushu & 41 \\
\hline December 2015 & Fujian Quanzhou & Wushu & 300 \\
\hline August 2015 & Beijing & Wushu & 101 \\
\hline & & & \\
\hline
\end{tabular}

Meanwhile, to promote Wushu, ethnic dance, folk music, and Chinese painting, and other Chinese culture deep into overseas Chinese society, so that Chinese culture can be effectively passed on to overseas Chinese and overseas Chinese, Overseas Chinese Affairs Office of the State Council invites overseas Chinese representatives from all over the country to visit China and the country. The Chinese language education base conducts various education and competition activities to spread Chinese culture, such as the "Chinese Talent Training Course for Overseas Chinese Cultural Societies", and classes of Wushu, ethnic dance, ethnic music, Chinese painting and other training courses have been held for more than 30 sessions ${ }^{2}$. Also, "Cultural China- Global Chinese Talent Competition for Chinese Talents", and competitions with Wushu, dragon boats, dragon dances, and ethnic dances as the main contents have been successfully held for 6 sessions ${ }^{3}$. Still, there are "Chinese Overseas Chinese Youth Culture Contest". These activities which play an important role in spreading the fine traditional Chinese culture in Domestic Chinese language schools and educational institutions are also very important carriers for transmitting Chinese culture overseas, as well as the best platform to gather the power of overseas compatriots and work with overseas compatriots for inheriting Chinese culture and realizing Chinese dream.

Currently, many domestic Chinese language education schools and institutions have successively carried out activities to transmit excellent Chinese culture such as Wushu, ethnic dance, and traditional Chinese painting in response to Chinese culture development strategy of. To adapt to the development of Chinese language education, the Overseas Chinese Affairs Office of the State Council established the "Chinese talented arts" Wushu training base in Jinan University in 2012, making Wushu a training 
content for domestic Chinese education activities. Its purpose is to spread Wushu culture to Chinese and overseas Chinese all over the world so that Wushu can be standardized, orderly spread around the world to cultivate reserve talent. With the profound cultural heritage and rich Wushu resources of the school, the base has set up annual Wushu training courses to train overseas Chinese from all over the world to better disseminate and promote Wushu and increase its reputation overseas influence. The main target of Wushu in domestic Chinese education schools and institutions is overseas Chinese and Chinese people from all over the world.

Practical survey of Wushu communication in overseas Chinese education.Not only effectively disseminated in Chinese language education in China, but also Wushu has entered many Confucius Institutes in the world as a carrier for spreading Chinese culture. The Confucius Institute is the educational and cultural exchange organization for promoting Chinese language and transmitting Chinese culture and Chinese culture established by the Office of the Leading Group for Teaching Chinese as a Foreign Language in different places of the world ${ }^{[3]}$. Since the establishment of the first Confucius Institute in Seoul on November 21, 2004, up to December 2015, China has established 500 Confucius Institutes and 1,000 Confucius Classrooms in 134 countries and regions on five continents, with registered trainee number of 1.9 million people initially, which has formed a multi-level, diversified, and widely-covered pattern ${ }^{[4]}$. Chinese Wushu played a significant role in the process of Confucius Institutes spreading Chinese culture to the world and promoting Chinese-foreign cultural exchanges, and transmitting a real China to the world. According to the 4th Confucius Institute Conference held in Beijing in December 2009, nearly 30\% of the 217 Confucius Institutes (classrooms) attending the conference have set up Wushu classes, including Tai Chi, Changquan, Kung Fu fans as the mostly instructed content ${ }^{[5]}$. It can be seen that Chinese Wushu in the Confucius Institute has huge influence. Therefore, in December 2009, Comrade Liu Yandong, the State Councilor and Chairman of the Confucius Institute Headquarters Council, spoke at the opening ceremony of the 4th Confucius Institute Conference, that Confucius Institutes should be flexible and actively develop own specialties when running schools. The curriculum and social service programs should be aimed at adults in universities, enterprises, and communities, primary and middle school students; aimed at both academic and non-academic education; focused on both language teaching, and cultural activities such as Chinese medicine, Wushu, and Beijing Opera." ${ }^{[6]}$ At the 6th national Wushu work conference, the task of "cooperating with the Hanban of China and developing Wushu as a teaching program in overseas cultural center and Confucius Institute" ${ }^{[8]}$ was clearly proposed; Liu Peng, Director General of the State Sports General Administration also emphasized again in 2013 The National Sports Directors' Conference, "negotiate with the Hanban on Wushu teaching activities in the Confucius Institute" ${ }^{[8]}$; Comrade Gao Xiaojun, the president of the Chinese Wushu Institute and director of the Wushu Sports Management Center of the National Sports General Administration, was the The 7th national Wushu work conference report once again proposed a new goal "Research and plan to promote Wushu pattern in Wushu Association and Confucius Institutes in various countries " ${ }^{[9]}$, he also suggested that" establish national Wushu pattern exam centers in Wushu Association and the Confucius Institute in each country. "[9]. Meanwhile, many experts and scholars have also conducted researches on the dissemination of Chinese Wushu at the Confucius Institute from different perspectives. For example, Zheng Jie in his master's thesis "Confucius Institute Wushu curriculum research" that participation and support of the Wushu classroom should be added for the sustainable development of the Confucius Institute, and the implementation of the Wushu class in the Confucius Institute will also bring far-reaching and extensive significance for the globalization promotion of Wushu ${ }^{[5]}$. Zhou Yaohu analyzed the feasibility and resistance factors of the Wushu course offered by the Confucius Institute in Bergen in his master thesis "Confucius Institute of Bergen Wushu Course Syllabus Design" by using the empirical research [10]. Pu Yizhe and Du Shushu concluded that the Confucius Institute with the mission of spreading Chinese culture is an effective model for promoting Wushu culture by taking Confucius Institute in South Korea as a research case. They also believe that the Confucius Institute is an important place for people in different countries to learn Wushu culture and understand China. ${ }^{[11]}$. Lou Dinghai and Zhang Maolin believe that Wushu and Confucius Institutes in line with the purpose of disseminating Chinese culture and proposed that Wushu has an extensive overseas foundation, which is 
conducive to promote Confucius Institute construction and establish Confucius Institute's educational characteristics ${ }^{[12]}$. Guo Yucheng and Li Shoupei believe that Wushu, as a typical representative of Chinese culture, needs to attract the state's attention when promoted to the Confucius Institutes. It is necessary to strengthen cooperation with relevant departments, formulate Wushu promotion plans, highlight the dissemination and guidance of Confucius Institutes around the world, and implement"big view of Wushu" to promote the implementation of Wushu standardization policies ${ }^{[13]}$. It can be seen from these research results that it is very common to transmit Wushu in Confucius Institutes around the world and the main target groups of Wushu at the Confucius Institute are non-Chinese people all over the world.

The task force also took field visit to investigate the situation ofWushucommunication in overseas Chinese schools. Wushu, also known as "national technique," is very popular in Southeast Asia, which has been carried out in Overseas Chinese schools in various countries. They regard "national technique" as the main content for promoting Chinese traditional culture and the main means for improving students' physique. For example, in Seoul Overseas Chinese Elementary School in Seoul, South Korea, "national technique" classes have been set up in both the normal teaching and the student's weekend interest classes. In Philippine Oro Christian Grace School and M isamisUnionHighSchool have both set up Wushu courses. Philippine Cultural College has its own Wushu team; Thailand Chongfahsinseung School also has set up Wushu class. Many other overseas Chinese schools have carried out Wushu content teaching. Wushu is not as popular in school for oversea Chinese astheConfucius Institute, but it has much longer historical origins than the Confucius Institutes. We can know that the Seoul Overseas Chinese Elementary School in Seoul, Korea, which was founded in 1909, has always taught the "national technique" content since its establishment. Meanwhile, Wushu also develops its due value and function in the overseas Chinese schools. The major target groups of Wushu overseas Chinese schools are mainly overseas Chinese and ethnic Chinese people around the world.

In recent years, to coordinate the development of Chinese education, the government has mobilized various forces and has actively carried out many effective work, such as the establishment of the "Chinese International Promotion WushuTeacher Training Base" at Beijing Sport University, "Introduce and go global" as the main form of Wushu training personnel training, expanding and upgrading the Chinese Wushu teachers force; also provided equipment and materials required for Chinese Wushu education schools and institutions.

In conclusion, Wushu which is highly favored by overseas students is emerging Chinese language education. However, there remains wide communication space and we need to further develop it.

\section{Problems and Countermeasures of Wushu Communication in World Chinese Education}

Problems of Wushu Communication.It can be seen from the results of the survey that Wushu is very popular among Chinese and foreign students in Chinese language education, which has occupied a place in Chinese language education. At the same time, during the inspection, we found a lot of deficiencies in Wushu communication in Chinese language education.

1)Lack of relevant Wushu communication materials. We found in our survey that overseas and domestic Chinese education schools and institutions have no matching Wushu materials. For example, we found that Wushu has only been briefly introduced in Volumes 1 and 2 of Wushu textbooks from the "Health and Sports" textbooks of overseas Chinese schools (secondary schools) in Korea, Malaysia, the Philippines, and Thailand. However, basketball, volleyball, football, badminton, track and field and other items have been arranged with contents in the 1-6 volumes of "Health and Sports" textbooks. Meanwhile, we found that many sports textbooks for overseas Chinese schools were published in Taiwan. Therefore, the texts in the textbooks are all in traditional characters, and the Wushu is also called "national techniques". According to the survey, no sports teaching materials and Wushu teaching materials were found in any overseas Confucius Institutes. However, as per the needs of our country's cultural communication strategy, the Office of the National Chinese Language International Promotion Leading Group has gradually carried forward the teaching materials of Wushu content. Domestic 
Chinese language education schools and institutions also use other non-Chinese language education schools' general sports teaching materials. For example, Chinese Language and Culture College of Huaqiao University, Collee of Chinese Language and Culture, Jinan University, Yunnan Chinese Language and Culture College of Yunnan Normal University apply the general sports teaching materials that are used in non-Chinese language education schools.

2)Single content of Wushu communication contents. It can be known from the survey that most Chinese schools and institutions only disseminated the technical movements of Wushu, and most of them focused on Tai Chi. Wushu cultural events such as the occurrence, development, history, etiquette, and related figures of Wushu were seldom transmitted. Also, the dissemination of equipment, such as squatting, picking, throwing, playing, and fighting was very few. It can be seen that the content of Wushu dissemination in Chinese language education is single, which cannot fully highlight the core of Wushu, or enable the target groups to understand a real China as the history of China is a history of Wushu.

3)Lack of high-quality Wushu transmitters.Excellent Wushu communicators who understand bilingual teaching, especially overseas Chinese education schools and institutions are in urgent demand. Many Wushu communicators from overseas Chinese education schools and institutions are part-time, not long-term teachers of the school or the institution, and are not Wushu majors. For example, during the on-site survey of five overseas Chinese schools in South Korea, we found that only one school had a full-time Wushu communicator, the other two were part-time Wushu communicators, and two did not set up Wushu courses because there was no Wushu communicator. In some overseas Confucius Institutes, most of communicators are part-time rather than full-time, who are temporary and staged communicators. And non-Chinese language education teachers serve as Wushu communicators of domestic Chinese-educated schools and institutions, which has greatly affected the effect of Wushu dissemination and also affected the development of Chinese language education even achieving "resource sharing".

4)Stagnant theoretical research. Theoretical research on the dissemination of Wushu in Chinese language education is deficient. If searching on HowNet and Wanfang database by inputting keywords such as Chinese education, Wushu, Wushu dissemination, Confucius Institute, overseas Chinese school, and Chinese language school, we found only 59 academic and dissertations from January 1980 to December 2015 studied related issues in Wushu by linking to Chinese education. According to statistical data, 58 research results were from scholars' researches on Wushu in Confucius Institutes and schools from different perspectives. However, the research results are very few compared to researches of Wushu in overseas Chinese schools, Chinese schools, Chinese schools and other world Chinese education schools and Institutions. Therefore, it can be seen that researches on Wushu communication in Chinese education is relatively single; the amount of theoretical research on Wushu in Chinese education is also relatively few.

Countermeasures ofWushu communication in world Chinese education."Communication is the essence of culture. Without communication, there will be no culture, and communication is the realization of culture. ${ }^{[14]}$ As a part of the Chinese traditional culture, Wushu plays an important role in spreading and promoting Chinese culture to the world. Therefore, Wushu shoulders the heavy responsibility of spreading Chinese culture to the whole world and promoting the healthy, scientific, and civilized communication in Chinese language education is one of the important ways to realize the prosperity of Chinese culture.

1)Strengthen the publicity of Wushu in world Chinese education. Relevant departments should mobilize the people, collect ideas, strengthen propaganda, and raise the awareness of the whole society about the importance of Chinese language education. Meanwhile, it is necessary to change the concept of education. In the Chinese language education, it should focus merely on language teaching, but should actively develop Wushu communication and other traditional Chinese culture in China; keep pace with the development of Chinese education, increase the awareness of the dissemination of Wushu in Chinese language education, enhance contact with relevant domestic organizations, get more people at home and abroad to understand Chinese education, and understand the importance and current difficulties of Wushu communication Chinese language education. 
2)Compile Wushu communication materials. Educator Pan Maoyuan indicated that one principle must be followed in the practice of Chinese language education, "Respect and abide by the relevant laws and education policies of the Chinese country, respect the overseas Chinese's own choices, and combine the actual conditions of overseas Chinese education to distinguish different situations and gradually solve them. It is not appropriate to insist on uniformity, or compulsory regulations. ${ }^{[15]}$ Therefore, when formulating specialized Chinese language education textbooks, Wushu knowledge can be compiled into Chinese education textbooks, or Wushu textbooks should be specifically designed for Chinese language education Several principles should be followed when compiling and formulating textbooks: Firstly, it should be suitable for image-based and different language versions of Wushu materials in different countries and regions. Secondly, the teaching materials should be well connected with Chinese language education. For example, cartoons are used to compile some materials related to Wushu, such as the anecdotes about Wushu, the occurrence of Wushu, the development of Wushu, Wushu celebrities, and Wushu, as well as the combination of language, culture, and culture. Thirdly, when selecting content, it is necessary to consider the condition of mass, and people of basic, high-level. Meanwhile, it should focus on both theoretical knowledge and technical knowledge in form of abundant images by combining with audiovisual materials.

3)Optimize Wushu transmitters. Wushu communicators are the primary factors that guarantee the quality and dissemination of Wushu. The Wushu communicators' mastery of Wushu knowledge and familiarity with technology are the key to the development of Wushu in Chinese language education. Overseas Wushu communicator's mastery of language in the teaching country is the basic condition for Wushu dissemination. Although there are many Wushu resources and "Wushu masters", many colleges and universities that train specialized Wushu talents in China, the deep cultural heritage and complicated technical movements of Wushu require bilingual communication, so that it will be difficult to correctly teach the students the essence of Wushu culture of the Wushu communicators have no mastery of language of the country. According to the survey, except for "Chinese International Wushu Teacher Training Base for Chinese International Promotion" of Beijing Sport University, no other teacher training schools and training institutions specializing in international dissemination of Wushu have been discovered yet. Relevant departments should provide relevant policies and cooperate with various specialized sports academies such as Beijing University of Physical Education and Shanghai Institute of Physical Education as well as normal colleges and universities to establish overseas Wushu dissemination schools and training institutions, and cultivate a large number of quality overseas Wushu communicators and serve the internationalization of Wushu communication.

4)Strengthen Wushu theoretical study in Chinese education.The task at this stage is to grasp the development opportunities brought by Chinese education, and examine and study the direction, and adapt to the reform and development of Chinese language education from new perspectives through new methods, strive to establish our own theoretical framework in this new field of Chinese language education and try to create new results in this research area. Meanwhile, to promote the internationalization of Wushu and the improvement of cultural soft power, relevant researchers should be encouraged to participate in and integrate into the field of Chinese education to conduct research, expand research space and research horizons, and explore more research starting points to sum up and summarize different rules to provide effective guidance for Wushu implementation in Chinese language education.

\section{Conclusion}

It can be found through practical investigation that Wushu has spread into Chinese education and communication system with extensive popularity among target groups. However, some practical problems have also been discovered during the survey such as lack of corresponding Wushu teaching materials, single content of Wushu, lack of high-quality Wushu communicators, and stagnant theoretical research. Therefore, under the background of big Chinese education development, it is necessary to enhance Wushu publicity in Chinese education and raise the awareness of the importance of Wushu dissemination in Chinese education so as to develop it in the new field of Chinese education, 
occupy their own "positions" and strive for sustainable dissemination. It is also necessary to combine with the actual conditions of Chinese education, and distinguish different situations and compile the corresponding Wushu communication materials. Relevant departments shall jointly establish overseas Wushu communication schools and training institutions to cultivate high quality overseas Wushu talents, for the purpose of healthy, scientific, civilized, and effective dissemination of Wushu in overseas and Chinese language education. Also, it is necessary to strengthen the theoretical research by combining with Confucius Institute research, overseas Chinese school research, TCSL theories, Chinese education theory, try to establish theoretical framework for Wushu communication in Chinese education so as to provide effective guidance for practical Wushu communication.

\section{References}

[1] Chen Zhen. Chinese education development trend and influence study under international background [J]. Journal of Yunnan Normal University, 2007, 5(2):38-42.

[2] Lin Putian. Tracing overseas Chinese education[J]. Overseas Chinese Education, 2000 (1) 22-26、 41.

[3] http://www.hanban.edu.cn

[4] http://conference.hanban.org

[5] Zheng Jie. Studies on Wushu course setting in Confucius Institute [D]. Taiyuan: North University of China, 2011: 4..

[6] Liu Yandong, the State Councilor and Chairman of the Confucius Institute Headquarters Council: Equal cooperation, innovative development, promote cultural exchanges and cooperation between China and foreign countries [N]. China Education Journal, 2009-12-23(1)

[7] State Physical Cultural Administration Wushu Sports Management Center: Five-year Plan for Chinese Wushu Development (2010-2014)[Z]. 2010: 3

[8] Speech of Director Liu Peng of State Physical Cultural Administration at National Sports Bureau Conference [Z]. 2013: 12.24

[9] State Physical Cultural Administration Wushu Sports Management Center. Speeches of the seventh national Wushu work conference and the tenth national wushu association election meeting[Z].2014: 2

[10] Zhou Yaohu: Confucius Institute of Bergen Wushu Course Syllabus Design [D]. Beijing: Beijing Sport University, 2011

[11] Pu Yizhe, Du Shuwen. Study on the International Communication of Wushu Culture Based on the Model of Confucius Institute: A Case Study of Korea [J]. Journal of Shenyang Institute of Physical Education, 2010, 29(1):125-128.

[12]Yu Dinghai, Zhang Maolin. Research on Wushu Promotion Mode Based on Confucius Institute [J]. Journal of Shanghai University Of Sport, 2011, 35(1):83-87.

[13] Guo Yucheng, Li Shoupei. Wushu communication in Confucius Institutes and the Construction of China's National Image [J]. Journal of Physical Education, 2013, 20(5):1-5.

[14] Ju Yan'an. Several issues about cultural communication [J]. Journal of Fudan University (Social Science Edition), 1986(3):49-55.

[15] Pan Hanyuan, Zhang Yingqiang. Highlights of Chinese Education and Modern Value of Chinese Excellent Traditional Culture [J]. Higher Education Study, 1998(3):12-15.

Data in (1)(2) are from different Chinese education bases in China 